\title{
Tumour growth stimulation after partial hepatectomy can be reduced by treatment with tumour necrosis factor $\alpha$
}

\author{
G. D. SLOOTER, R. L. MARQUET, I. JEEKEL and J. N. M. IJZERMANS \\ Department of Sungery, Erasmus University, Rotterdam, The Netherlands \\ Correspondence to: Dr R. L. Marquet, Laboratory for Experimental Surgery, Erasmus University, PO Box 1738, 3000-DR Rotterdam, \\ The Netherlands
}

\begin{abstract}
This study investigated whether partial hepatectomy enhances the growth of experimental liver metastases of colonic carcinoma in rats and whether treatment with recombinant human tumour necrosis factor (TNF) $\alpha$ can reduce this increased growth. Resection of 35 or 70 per cent of the liver was performed in inbred WAG rats, with shamoperated controls (five to eight animals per group). Immediately after surgery $5 \times 10^{5}$ CC531 colonic tumour cells were injected into the portal vein. After 28 days the animals were killed and the number of liver metastases counted. A 35 per cent hepatectomy induced a significant increase in the median number of liver metastases (28 versus 3 in controls), whereas a 70 per cent resection
\end{abstract}

provoked excessive growth, consistently leading to more than 100 liver metastases and a significantly increased wet liver weight in all animals. TNF- $a$ was given intravenously to rats following 70 per cent hepatectomy or sham operation in a dose of $160 \mu \mathrm{g} / \mathrm{kg}$ three times per week. This had only a marginal effect on tumour development in sham-operated rats but was very effective following partial hepatectomy (median 45 liver metastases). These observations confirm previous findings that surgical metastasectomy may act as a 'double-edged sword' by provoking outgrowth of dormant tumour cells and suggest that adjuvant treatment with TNF- $\alpha$ may be of benefit in patients undergoing resection of metastases.
Surgical excision by partial hepatectomy is the only available method for prolonging the survival of patients with hepatic metastases from colorectal carcinoma. The 5-year survival rate of patients eligible for surgical resection (i.e. those with a solitary metastasis or a small tumour burden confined to the liver) is $25-40$ per cent ${ }^{1-4}$. These results compare favourably with the natural outcome for this selected group of patients, who have a 5-year survival rate of less than 1 per cent ${ }^{1,4}$. However, despite the curative potential of hepatic resection, recurrence has been reported in 65-80 per cent of patients ${ }^{2-4}$, the majority being diagnosed within the first year after operation ${ }^{2,3}$. This suggests that the period immediately after resection may be of crucial importance for prognosis.

It is obvious that the favourable survival rates achieved by surgery validate a continued policy of resection of metastatic liver disease. On the other hand, the high number of early recurrences suggests that resection might provoke enhanced tumour growth of occult metastases. Experimental research may provide clues for a modified surgical strategy or appropriately timed adjuvant therapy.

Several groups have found experimental evidence for stimulation of tumour growth by partial hepatectomy in various animal models; both intrahepatic lesions and subcutaneously transplanted tumours were found to grow more quickly after this operation ${ }^{5-9}$.

There are various explanations for this phenomenon. Growth factors produced by the regenerating liver, such as hepatocyte growth factor, transforming growth factor $\beta$ and epidermal growth factor, have been implicated as tumour growth-promoting agents ${ }^{10-12}$. Other possible mechanisms include the detrimental effect of surgical manipulation ${ }^{13}$, the generalized immunosuppression provoked by partial resection ${ }^{14}$ and impaired Kupffer cell function ${ }^{15}$. The aim of the present study was to investigate whether evidence could

Presented to the 84th annual meeting of the American Association for Cancer Research in Orlando, Florida, USA, May 1993

Paper accepted 13 April 1994 be found for enhanced growth of fresh liver metastases after partial resection in a rat model of colonic adenocarcinoma. Furthermore, it was investigated whether the putative growth stimulation could be inhibited or reversed by adjuvant treatment with tumour necrosis factor (TNF) $\alpha$, an agent with proven efficacy against the colonic tumour under investigation $^{16}$.

\section{Materials and methods \\ Animals and tumour}

Male inbred WAG rats, 10-14 weeks old, weighing $250-275 \mathrm{~g}$, and bred under specific pathogen-free conditions, were used. The rats were given standard rat food and water ad libitum. The experimental protocol adhered to rules laid down by the Dutch Animal Experimentation Act and was approved by the Committee on Animal Research of Erasmus University.

Tumour CC531 is a moderately differentiated, weakly immunogenic colonic adenocarcinoma induced in a WAG rat by 1,2-dimethylhydrazine ${ }^{17}$. The tumour is maintained in tissue culture as a monolayer in RPMI 1640 medium (Gibco, Paisley, UK), supplemented with 5 per cent fetal calf serum. A total of $5 \times 10^{5}$ cultured tumour cells were injected into the portal vein. The cells were harvested from stationary cultures by gentle trypsinization, providing cell suspensions with a viability greater than 95 per cent. Tumour CC531 is relatively insensitive to chemotherapy, but sensitive to the effects of biological response modifiers such as the interferon inducer bropirimine, interferon $\gamma$ and TNF- $\alpha^{16}$.

\section{Experimental procedure}

Under ether anaesthesia the abdomen was opened through a midline incision. The left lateral and median liver lobes, representing 70 per cent of the liver volume, were freed of fibrous attachments and exteriorized. The circulation in these lobes was temporarily interrupted by ligation of the hilar vessels. CC531 tumour cells in $0.2 \mathrm{ml}$ RPMI 1640 were injected into the portal vein through a $0.4 \times 12-\mathrm{mm}$ needle. Over $2 \mathrm{~min}$ the cells were directed through the remaining 30 per cent of the liver that was not ligated. The rats were then randomized into a partial hepatectomy group and a non-hepatectomy (sham) group. In the 70 per cent 
hepatectomy group the temporary ligation was replaced by a permanent $2 / 0$ silk tie and the ligated lobes were resected. In the 35 per cent hepatectomy group only the left lateral lobe was resected. In the sham group the temporary ligation was removed to reestablish the circulation. The liver was then returned to the peritoneal cavity and the laparotomy wound closed in one layer.

The rats were killed after 28 days by an overdose of ether. The liver was removed, immersed in phosphate-buffered saline (PBS), and tumour growth was determined by counting the number of metastases on the surface of the liver lobes. The livers were put on blotting paper for $30 \mathrm{~s}$ to remove excess PBS and were then weighed immediately. Experimental groups contained five to eight animals.

\section{Tumour necrosis factor $\alpha$}

TNF- $\alpha$ was provided in lyophilized form by Knoll (Ludwigshafen, Germany). The product was 99 per cent pure, contained less than $10 \mathrm{pg}$ endotoxin per $\mathrm{mg}$ protein and had a specific activity of $6.63 \times 10^{6}$ units $/ \mathrm{mg}$. It was reconstituted in PBS before injection and was given intravenously in a dose of $160 \mu \mathrm{g} / \mathrm{kg}$ in $0.2 \mathrm{ml} \mathrm{PBS}$, three times per week, starting on the day of operation. Control treatment consisted of $0.2 \mathrm{ml}$ PBS according to the same schedule. On completion of sham operation or 70 per cent hepatectomy the rats were randomized and assigned to control or TNF- $\alpha$ treatment.

\section{Statistical analysis}

The number of tumour colonies on the surface of the liver lobes was counted. When more than 100 metastases were present, the number was scored as $>100$. Results were analysed with the MannWhitney $U$ test for comparison of non-parametric data and expressed as median (range). The mean liver weight was compared using Student's unpaired $t$ test. Significance was accepted at $P<0.05$.

\section{Results}

\section{Effect of partial hepatectomy on tumour growth}

The numbers of metastases 28 days after 35 or 70 per cent hepatectomy are shown in Table 1 . A 35 per cent resection induced a significant increase in the number of metastases $(P=0.044)$ but not in wet liver weight. The number of tumours in the control group ranged from 0 to 20 (median 3 ), and from 10-57 (median 28) in the 35 per cent hepatectomy group. A 70 per cent resection induced an even greater increase in tumour development. In all rats receiving this operation the number of tumours exceeded 100, whereas that in the controls ranged from 0 to 31 (median 7 ). Following 70 per cent hepatectomy there also was a significant increase in wet liver weight $(P=0 \cdot 006)$. The experiment involving 70 per cent resection was repeated four times, each time giving similar, significant, results. Fig. 1 shows the explosive tumour growth in a 70 per cent resected

Table 1 Liver metastasis and wet liver weight 28 days after tumour cell injection

\begin{tabular}{|c|c|c|c|}
\hline Operation & Incidence & $\begin{array}{l}\text { Median (range) } \\
\text { no. of } \\
\text { metastases }\end{array}$ & $\begin{array}{l}\text { Mean(s.d.) } \\
\text { wet liver } \\
\text { weight (g) }\end{array}$ \\
\hline $\begin{array}{l}70 \text { per cent hepatectomy } \\
\text { Sham* }\end{array}$ & $\begin{array}{l}6 \text { of } 6 \\
5 \text { of } 6\end{array}$ & $\begin{array}{l}>100 \dagger \\
\quad 7(0-31)\end{array}$ & $\begin{array}{l}22 \cdot 5(8 \cdot 9) \ddagger \\
10 \cdot 6(0 \cdot 9)\end{array}$ \\
\hline $\begin{array}{l}35 \text { per cent hepatectomy } \\
\text { Sham* }\end{array}$ & $\begin{array}{l}5 \text { of } 5 \\
5 \text { of } 6\end{array}$ & $\begin{array}{c}28(10-57) \dagger \\
3(0-20)\end{array}$ & $\begin{array}{l}10 \cdot 5(1 \cdot 3) \\
10 \cdot 2(0 \cdot 3)\end{array}$ \\
\hline
\end{tabular}

* Remaining lobes ligated during injection of tumour cells, but not removed. $† P<0.05$ versus sham (Mann-Whitney $U$ test); $\ddagger P<0.05$ versus sham (Student's $t$ test) liver and can be compared with the appearance of a control liver in Fig. 2. In sham-operated rats no tumour was found in any of the lobes ligated during tumour cell injection.

\section{Antitumour effect of tumour necrosis factor $\alpha$}

The results of treatment of sham-operated and 70 per cent hepatectomized rats with TNF- $\alpha$ are shown in Table 2 . In the

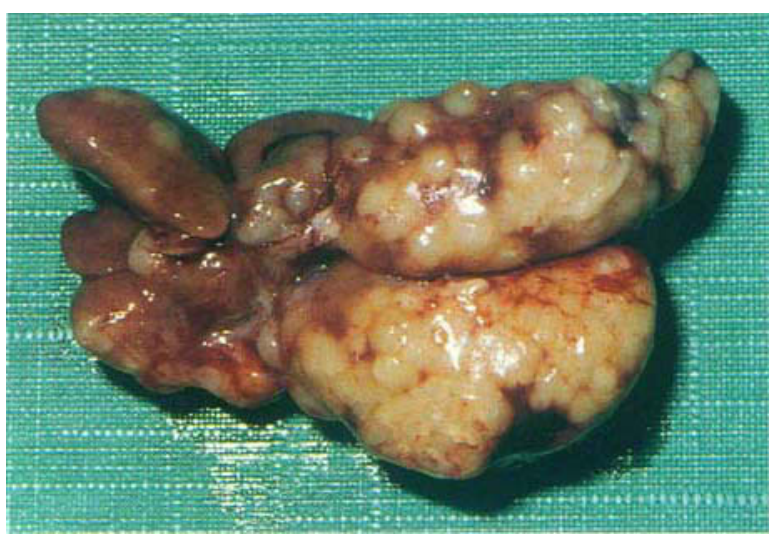

Fig. 1 Tumour growth following 70 per cent hepatectomy

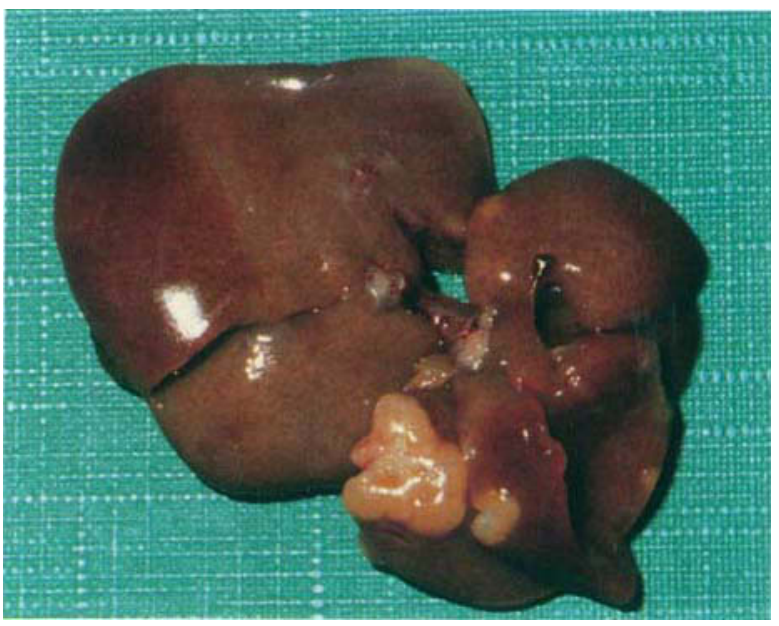

Fig. 2 Tumour growth following sham operation

Table 2 Effect of tumour necrosis factor $\alpha$ on growth of liver metastases 28 days after 70 per cent hepatectomy or sham operation

\begin{tabular}{|c|c|c|c|}
\hline & Incidence & $\begin{array}{l}\text { Median (range) } \\
\text { no. of } \\
\text { metastases }\end{array}$ & $\begin{array}{l}\text { Mean(s.d.) } \\
\text { wet liver } \\
\text { weight (g) }\end{array}$ \\
\hline \multicolumn{4}{|c|}{ TNF- $\alpha$ treatment } \\
\hline 70 per cent hepatectomy & 6 of 6 & $45(5->100) \dagger$ & $12 \cdot 4(6 \cdot 4)$ \\
\hline Sham* & 2 of 5 & $0(0-7)$ & $9 \cdot 0(0 \cdot 6)$ \\
\hline \multicolumn{4}{|l|}{ Control treatment } \\
\hline 70 per cent hepatectomy & 5 of 5 & $>100 \ddagger$ & $22 \cdot 3(8 \cdot 4) \S$ \\
\hline Sham* & 5 of 8 & $3 \cdot 5(0->100)$ & $8 \cdot 7(1 \cdot 2)$ \\
\hline
\end{tabular}

TNF, tumour necrosis factor. ${ }^{*}$ Remaining lobes ligated during injection of tumour cells, but not removed. $\dagger P<0.05$ versus sham and 70 per cent hepatectomy control treatment; $\ddagger P<0.05$ versus sham (Mann-Whitney $U$ test). $\S P<0.05$ versus sham (Student's $t$ test) 
sham-operated group treatment with TNF- $\alpha$ had no significant effect on tumour growth compared with that in non-treated sham-operated controls (range 0-7 versus $0->100$ tumours respectively). Following 70 per cent resection, treatment with $\mathrm{TNF}-\alpha$ was very effective and resulted in a significant inhibition of tumour growth: range $5->100$ (median 45) tumours in the treated group versus $>100$ tumours in all non-treated animals. The decrease in tumour load following TNF- $\alpha$ treatment was confirmed by a significantly decreased mean(s.d.) liver weight $(12 \cdot 4(6 \cdot 4)$ versus $22 \cdot 3(8 \cdot 4) \mathrm{g}$ respectively). Clinical signs of toxicity due to TNF- $\alpha$ treatment were not observed.

\section{Discussion}

The first finding in these experiments is that partial hepatectomy provokes increased tumour growth in the liver remnant. In repeated experiments an increase was found in wet liver weight and in the number of tumours after partial hepatectomy. To investigate whether the degree of growth promotion was proportional to the amount of liver resected, the effects of 70 and 35 per cent hepatectomy were compared, and it was found that this was indeed the case. Although both procedures significantly increased tumour growth, the effect of a 70 per cent resection was far greater. These findings confirm previous results obtained with various tumour models in rats ${ }^{5-9}$. Using the same CC531 tumour model as described in the present study, K. P. de Jong et al. (personal communication) recently found that partial hepatectomy also enhances the growth of established liver metastases. It thus appears that, in this model, partial resection affects not only the outgrowth of fresh artificial metastases but also the proliferation of established tumours, thereby mirroring the clinical situation to an even greater degree. However, results of studies performed predominantly in mice disagreed with these findings, and showed that partial resection did not lead to stimulation of tumour growth but rather to growth inhibition ${ }^{18-20}$. The inhibition of growth observed in the latter models has been ascribed to the immunostimulatory effects of partial resection, whereas immunosuppression and the release of growth factors have been held responsible for the enhanced tumour growth in rats. In the present rat model a likely explanation for the observed effect of partial resection is immunosuppression. A previous study ${ }^{21}$ showed that tumour CC531, which is weakly immunogenic, exhibits enhanced growth when recipients are treated with the immunosuppressive drug cyclosporin. In addition, Heuff et al..$^{22}$, using exactly the same model as the present authors ${ }^{21}$, found that selective elimination of Kupffer cells resulted in strongly enhanced growth of liver metastases, similar to the explosive growth following partial resection in the present study. Although there is no direct evidence, it is tempting to speculate that partial resection leads to a depression of the natural cytotoxicity normally exhibited by Kupffer cells, resulting in accelerated tumour growth.

There are various theories regarding the origin of new metastases in the liver that give rise to detectable recurrence. Tumour cells can spread from primary tumour cells in the liver remnant or from extrahepatic secondaries to form de novo metastases in the liver. Also, tumour cells that are spread during partial hepatectomy can settle again in the liver $^{1}$. However, it is most likely that micrometastases not detected by preoperative or intraoperative screening grow to form detectable metastases ${ }^{23,24}$. It has been suggested ${ }^{8}$ that most of the occult metastases are single tumour cells that are spread throughout the liver. These dormant tumour cells could be triggered to start proliferating by changes in extracellular host factors. Liver regeneration after partial resection could provide such a trigger for metastatic growth. It is conceivable that, in this phase of tumour devetopment, adjuvant therapy would be particularly effective.

Treatment with TNF- $\alpha$ was found to reduce the number of metastases in the liver remnant. The antitumour effect was more prominent in regenerating than in sham-operated liver, suggesting that the process of regeneration provides optimal conditions for TNF- $\alpha$ to be effective. However, tumour growth in the sham-operated livers was low, so firm conclusions on the relative inadequacy of TNF- $\alpha$ in nonhepatectomized livers cannot be drawn.

Earlier studies on the efficacy of adjuvant therapy following partial resection in the rat provided evidence that 5-fluorouracil (5-FU) and mitomycin $\mathrm{C}$ both were effective in reducing the enhanced tumour growth ${ }^{9}$. However, whereas the effect of mitomycin was found to be due to direct antitumour cytotoxicity, that of 5-FU was indirect and could be ascribed to inhibition of liver regeneration. In the present study the inhibition of tumour growth by TNF- $\alpha$ was not likely to be due to inhibition of liver regeneration. A pilot study has shown that treatment with TNF- $\alpha$ in doses ranging from 10 to $160 \mu \mathrm{g} / \mathrm{kg}$ on days 0 and 3 does not affect liver regeneration as assessed by wet liver weight on day 6 after 70 per cent hepatectomy (unpublished results). In addition, repeated injection of TNF- $\alpha$ to hepatectomized and intact rats stimulates DNA synthesis in hepatocytes, resulting in an increased liver cell mass ${ }^{25,26}$. If confirmed, these latter findings imply that, depending on dose and timing of administration, TNF- $\alpha$ may show two opposing effects: inhibition of tumour growth on the one hand and a counterproductive stimulation of liver regeneration on the other. In the clinical situation this undesired effect might be counteracted by combining TNF- $\alpha$ with chemotherapy.

The clinical results obtained so far with systemic administration of TNF- $\alpha$ have not met the expectations raised by numerous animal studies ${ }^{27}$. The few studies ${ }^{28,29}$ performed with TNF- $\alpha$ in patients with colorectal cancer have provided no evidence of antitumour efficacy. However, interest in using TNF- $\alpha$ clinically has recently been rekindled by the remarkable efficacy of locoregional treatment with TNF- $\alpha$ (combined with interferon $\gamma$ and chemotherapy) in patients with melanoma and sarcoma ${ }^{30,31}$. In agreement with this new approach are the positive results obtained with locoregional treatment of liver metastases from patients with colorectal cancer. Van der Schelling et $a l^{32}$ found stable disease after injection of TNF- $\alpha$ directly into liver metastases, whereas Mavligit and colleagues ${ }^{33}$ observed a 14 per cent partial tumour response following TNF- $a$ infusion via the hepatic artery. These studies indicate that TNF- $\alpha$ has definite antitumour activity in colorectal cancer metastatic to the liver. This observation, combined with the results obtained in the present study, supports the notion that a combination of metastasectomy and locoregional adjuvant therapy with TNF- $\alpha$, preferably combined with chemotherapy, may be of benefit in patients with liver metastases from colorectal cancer.

\section{Acknowledgements}

This work was supported by a grant from the Dutch Organisation for Scientific Research. 


\section{References}

1 Ballantyne GH, Quin J. Surgical treatment of liver metastases in patients with colorectal cancer. Cancer 1993; 71(Suppl): 4252-66.

2 Hughes KS, Simon R, Songhorabodi S et al. Resection of the liver for colorectal carcinoma metastases: a multi-institutional study of patterns of recurrence. Surgery $1986 ; 100: 278-4$.

3 Steele G Jr, Ravikumar TS. Resection of hepatic metastases from colorectal cancer: biologic perspectives. Ann Surg 1989; 210: 127-38.

4 Scheele J, Stangl R, Altendorf-Hofmann A. Hepatic metastases from colorectal carcinoma: impact of surgical resection on the natural history. Br J Surg 1990; 77: 1241-6.

5 Fisher B, Fisher ER. Experimental studies of factors influencing hepatic metastases: II. Effect of partial hepatectomy. Cancer 1959; 12: 929-32.

6 Paschkis KE, Cantarow A, Stasney J, Hobbs JH. Tumor growth in partially hepatectomized rats. Cancer Res 1955; 15: 579-82.

7 Loizidou MC, Lawrance RJ, Holt S et al. Facilitation by partial hepatectomy of tumor growth within the rat liver following intraportal injection of syngeneic tumor cells. Clin Exp Metastasis 1991; 9: 335-49.

8 Panis Y, Ribeiro J, Chrétien Y, Nordlinger B. Dormant liver metastases: an experimental study. Br J Surg 1992; 79: 221-3.

9 Mizutani J, Hiraoka T, Yamashita R, Miyauchi Y. Promotion of hepatic metastases by liver resection in the rat. $\mathrm{Br} J$ Cancer 1992; 65: 794-97.

10 Michalopoulos GK. Liver regeneration: molecular mechanisms of growth control. FASEB $J$ 1990; 4: 176-87.

11 Kaneko A, Hayashi N, Tanaka Y et al. Changes in serum human hepatocyte growth factor levels after transcatheter arterial embolization and partial hepatectomy. Am J Gastroenterol 1992; 87: 1014-17.

12 Jiang WG, Lloyds D, Puntis MCA, Nakamura T, Hallet MB. Regulation of spreading and growth of colon cancer cells by hepatocyte growth factor. Clin Exp Metastasis 1993; 11: 235-42.

13 Fisher B, Fisher ER. Experimental studies of factors influencing hepatic metastases. III: Effect of surgical trauma with special reference to liver injury. Ann Surg 1959; 150: 731-44.

14 Panis Y, Nordlinger B, Uliveri JM, Herve JP, Delelo R, Ballet F. An experimental model of colon cancer in the rat. Effects of surgical trauma and immunosuppression on colonic carcinogenesis and spontaneous liver metastases. Surgical Research Communications 1991; 11:99-105.

15 Pearson HJ, Anderson J, Chamberlain J, Bell PRF. The effect of Kupffer cell stimulation or depression on the development of liver metastases in the rat. Cancer Immunol Immunother 1986; 23: $214-16$.

16 Marquet RL, IJzermans JNM, de Bruin RWF, Fiers W, Jeekel J. Anti-tumor activity of recombinant mouse tumour necrosis factor (TNF) on colon cancer in rats is promoted by recombinant rat interferon gamma; toxicity is reduced by indomethacin. Int J Cancer 1987; 40: 550-3.
17 Marquet RL, Westbroek DL, Jeekel J. Interferon treatment of a transplantable colon adenocarcinoma; importance of tumor site. Int $J$ Cancer 1984; 33: 689-92.

18 Ono $\mathrm{M}$, Tanaka $\mathrm{N}$, Orita $\mathrm{K}$. Complete regression of mouse hepatoma transplanted after partial hepatectomy and the immunological mechanism of such regression. Cancer Res 1986; 46: 5049-53.

19 Castillo MH, Doerr RJ, Paolini N Jr, Cohen S, Goldrosen M. Hepatectomy prolongs survival of mice with induced liver metastases. Arch Surg 1989; 124: 167-9.

20 Doerr R, Castillo M, Evans P, Paolini N Jr, Goldrosen M, Cohen SA. Partial hepatectomy augments the liver's antitumor response. Arch Surg 1989; 124: 170-4.

21 Van de Vrie W, Gheuens EEO, Durante NMC et al. In vitro and in vivo chemosensitizing effect of cyclosporin $\mathrm{A}$ on an intrinsic multidrug-resistant rat colon tumour. J Cancer Clin Oncol 1993; 119: 609-14.

22 Heuff G, Oldenburg HSA, Boutkan $\mathrm{H}$ et al. Enhanced tumour growth in the rat liver after selective elimination of Kupffer cells. Cancer Immunol Immunother 1993; 37: 125-30.

23 Finlay IG, McArdle CS. Occult hepatic metastases in colorectal carcinoma. Br J Surg 1986; 73: 732-5.

24 Charnley RM, Morris DL, Dennison AR, Amar SS, Hardcastle JD. Detection of colorectal liver metastases using intraoperative ultrasonography. BrJ Surg 1991; 78: 45-8.

25 Beyer HS, Stanley M. Tumor necrosis factor- $\alpha$ increases hepatic DNA and RNA and hepatocyte mitosis. Biochem Int 1990; 22: 405-10.

26 Feingold KR, Soued M, Grunfeld C. Tumor necrosis factor stimulates DNA synthesis in the liver of intact rats. Biochem Biophys Res Commun 1988; 153: 576-82.

27 Frei E III, Spriggs D. Tumor necrosis factor: still a promising agent. J Clin Oncol 1989; 3: 291-4.

28 Schaadt M, Pfreundschuh M, Lorscheidt G, Peters KM, Steinmetz T, Diehl V. Phase II study of recombinant human tumor necrosis factor in colorectal carcinoma. Journal of Biological Response Modifiers 1989; 9: 247-50.

29 Fiedler W, Zeller W, Peimann CJ, Weh HJ, Hossfeld DK. A phase II combination trial with recombinant human tumor necrosis factor and gamma interferon in patients with colorectal cancer. Klin Wochenschr 1991; 69: 261-8.

30 Lienard D, Ewalenko P, Delmotte JJ, Renard N, Lejeune FJ. High-dose recombinant tumor necrosis factor alpha in combination with interferon gamma and melphalan in isolation perfusion of the limbs for melanoma and sarcoma. J Clin Oncol 1992; 10: 52-60.

31 Hill S, Fawcett WJ, Sheldon J, Soni N, Williams T, Thomas JM. Low-dose tumour necrosis factor $\alpha$ and melphalan in hyperthermic isolated limb perfusion. Br J Surg 1993; 80: 995-7.

32 Van der Schelling GP, IJzermans JNM, Kok TC et al. A phase I study of local treatment of liver metastases with recombinant tumour necrosis factor. Eur J Cancer 1992; 28A: 1073-8.

33 Mavligit GM, Zukiwski AA, Charnsangavej $\mathrm{C}$, Carrasco $\mathrm{CH}$, Wallace $\mathrm{S}$, Gutterman JU. Hepatic arterial infusion of recombinant human tumor necrosis factor in patients with liver metastases. Cancer 1992; 69: 557-61. 